\title{
The source rupture process of the Great Banda Sea earthquake of November 4, 1963
}

\author{
Joan L. Welc and Thorne Lay \\ Department of Geological Sciences, University of Michigan, Ann Arbor, MI 48109 (U.S.A.)
}

\begin{abstract}
Welc, J.L. and Lay, T., 1987. The source rupture process of the Great Banda Sea earthquake of November 4, 1963. Phys. Earth Planet. Inter., 45: 242-254.

The Banda Sea earthquake of November 4, 1963 is one of the largest $\left(M_{W}=8.3\right)$ intraplate events. It involved oblique thrusting at an intermediate depth within the subducted lithosphere near the abrupt bend in the southeastern Banda arc $\left(6.86^{\circ} \mathrm{S}, 129.58^{\circ} \mathrm{E}\right)$. To better understand the tectonic significance of this earthquake, the detailed source process of the Banda Sea event was determined by body wave analysis. The rupture history was established by deconvolving source time functions from long-period $\mathrm{P}$ wave seismograms, using both individual station and multi-station time-domain deconvolution methods. The seismic moment release occurred within the first $50 \mathrm{~s}$ of rupture, initiating at a depth near $120 \mathrm{~km}$ and expanding laterally and downdip over a vertical extent of about $50 \mathrm{~km}$. Slip and moment release were concentrated in one main region near the hypocenter, at depths between 110 and 130 km. The along-strike rupture length was only about $100 \mathrm{~km}$, so it is difficult to resolve any horizontal directivity. The compressional stress orientation inferred from the focal mechanism parallels the strike of the slab, and reflects the importance of contortion of the lithosphere in this region. The Banda Sea event may be part of a major detachment at the leading edge of the subducted Australian continental shelf.
\end{abstract}

\section{Introduction}

Detailed analyses of great intraplate earthquakes provide important information about deformation of subducted lithosphere and the nature of the subduction process. Notable examples include the $M_{W}=8.51933$ Sanriku earthquake (Kanamori, 1971) and the $M_{W}=8.31977$ Sumba earthquake (Silver and Jordan, 1983; Lynnes et al., 1985; Spence, 1986), both of which represent deformation of the subducting plate at shallow depths beneath the respective oceanic trenches. Interpreting these earthquakes requires accurate knowledge of the extent of rupture and the detailed source processes of the events, which can only be obtained by body wave and surface wave analysis. Another great intraplate earthquake occurred at a greater depth of $100-150 \mathrm{~km}$ at the curved eastern end of the Banda arc on November 4, 1963. The Banda arc (Fig. 1), located northwest of Australia, involves subduction along the Java
trench-Timor trough-Aru trough system, and separates the Indian Ocean-Australian plate from the Eurasian or Southeast Asian plate (Fitch, 1972; Cardwell and Isacks, 1978). The large size of this event, $M_{W}=8.3$, indicates that the Banda Sea earthquake is a manifestation of a major tectonic process occurring at the eastern end of the Banda arc.

This study analyzes the source process of the 1963 Banda Sea earthquake using long-period body waves, and complements the analysis of longperiod surface waves by Osada and Abe (1981). In addition to being one of the largest intraplate events since deployment of the World-Wide Standard Seismograph Network (WWSSN), the Banda Sea event is particularly interesting because it occurred in a region of strongly contorted lithosphere in a subduction zone where continental crust has impinged upon the trench modifying its geometry (Fig. 1). 


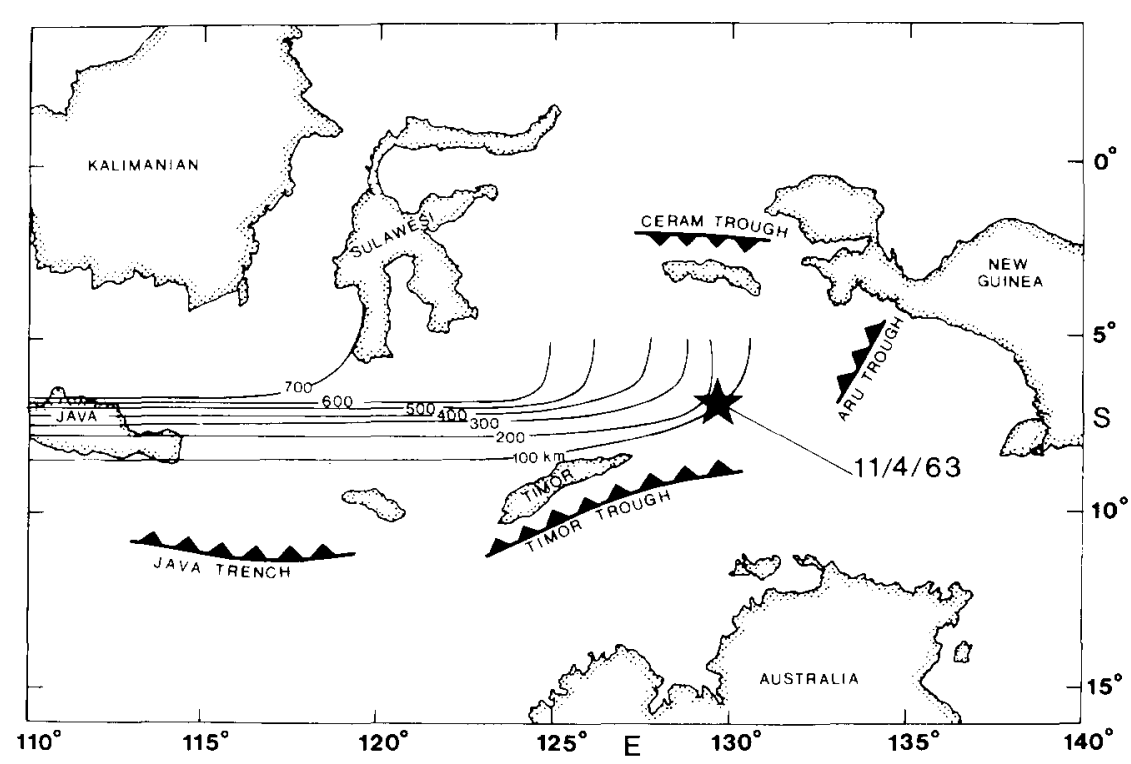

Fig. 1. Map of the Banda arc and eastern Indonesia showing the location of the 1963 Banda Sea earthquake. The solid curves are seismic depth contours in kilometers (Cardweli and Isacks, 1978).

\section{P waves from the 1963 Banda Sea Earthquake}

Representative $P$ waves from the Banda Sea event recorded on long-period instruments at WWSSN stations are shown in Fig. 2, along with the focal mechanism and $P$ wave first motions determined in this study. In picking the onset of the $\mathrm{P}$ waves, we utilized the redetermined source origin time of Osada and Abe (1981) [01 : $17: 11.4]$, which has some uncertainty due to interference from a large New Hebrides event that occurred about 3 min earlier.

The $\mathrm{P}$ waveforms generally exhibit a bimodal distribution of waveshapes with substantially different character. The characteristic waveform observed at azimuths from $30-140^{\circ}$ is illustrated by the North American stations MDS, GOL, and TUC in the northeast quadrant of the focal sphere. The $P$ waves are relatively simple, with emergent onsets followed by a broad, large amplitude arrival $50 \mathrm{~s}$ into the signals. The second characteristic $P$ waveshape was recorded by stations at azimuths of $240-360^{\circ}$. Figure 2 shows representative examples of $\mathbf{P}$ waves recorded at European stations in the northwest quadrant of the focal sphere, which have strong, impulsive arrivals in the first $30 \mathrm{~s}$ of the signals and greater complexity $70 \mathrm{~s}$ into the records than the northeastern observations. The signal at station LPA (azimuth $=170^{\circ}$ ) is transitional in character, with a smooth waveform like those to the northeast, yet strong first arrivals as in those to the northwest. Most of these waveform variations result from the oblique component in the predominantly thrust mechanism, although the differences in complexity late in the waveforms indicate a complicated radiation or Earth structure effect. The azimuthal coverage of the southern part of the focal sphere is quite poor.

Horizontal components and diffracted $P$ waves were used to study this great event because many of the vertical components of non-diffracted $P$ waves were off-scale and the global station distribution is relatively poor for this source region. Records from 33 stations were obtained. Amplitude corrections were made for the horizontal components to simulate vertical recordings. In cases where both the horizontal and partial vertical components were available, the correction was made by taking the ratio of the horizontal amplitude to the vertical amplitude from the on-scale 


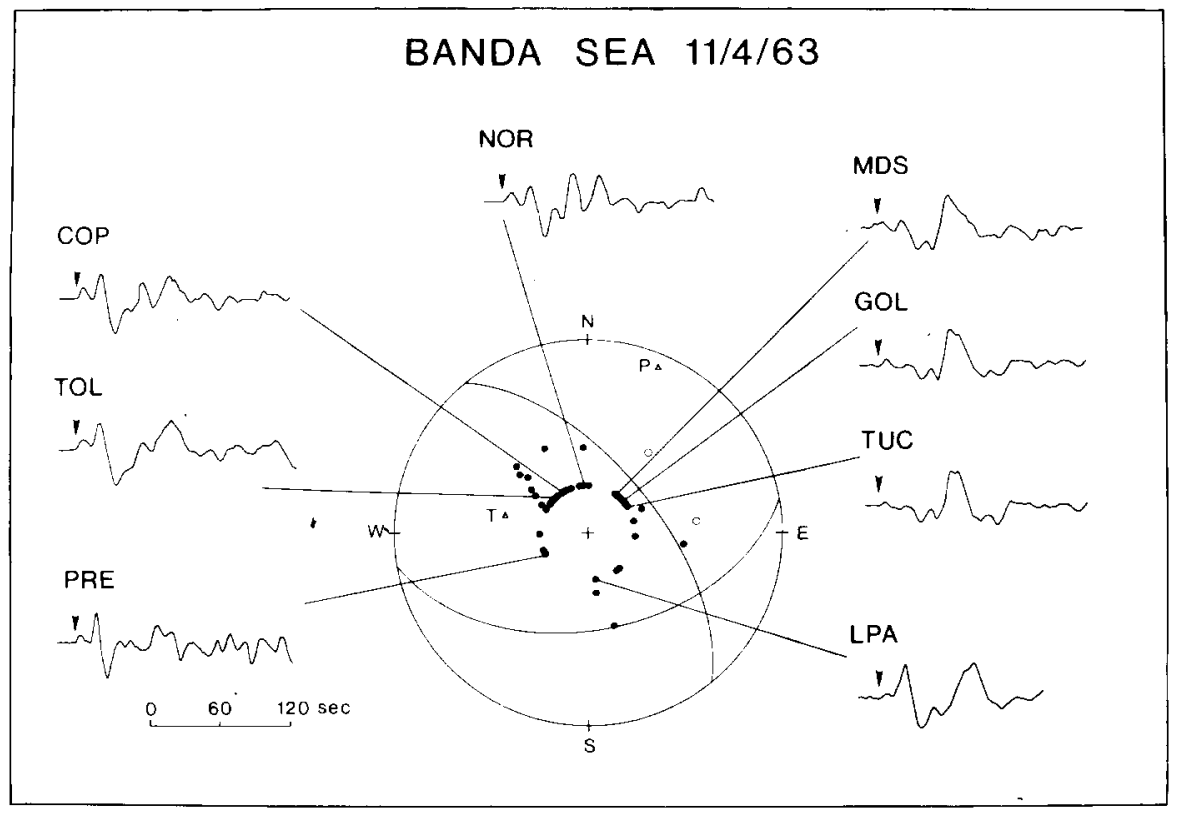

Fig. 2. Lower hemisphere, equal area focal mechanism for the 1963 Banda Sea earthquake with $P$ wave first motion observations and representative long-period $\mathrm{P}$ waveforms. The solid circles indicate compressional first motions, open circles indicate dilatations. The strike of the fault plane is $\mathrm{N} 80^{\circ} \mathrm{E}$, and the rake of $40^{\circ}$ was constrained to satisfy both P-wave and surface-wave observations.

portion of the records. For stations where vertical components were not available or had no on-scale pulses, a theoretical amplitude correction was made for the receiver function (Bullen, 1963). The amplitudes were not corrected for diffraction effects. Core diffraction attenuates high frequencies more readily than low frequencies, therefore diffracted $\mathrm{P}$ waves are a smoothed version of the non-diffracted signals. Although the high frequencies are lost, the long-period information, which forms the main features of the seismogram, is retained (Ruff and Kanamori, 1983). The source time functions obtained by deconvolution of diffracted $P$ waves are consequently smoothed, yet they still exhibit the primary features of moment release which reveal the spatial and temporal history of the rupture. However, since the amplitudes are not corrected for diffraction effects, the seismic moments obtained from the deconvolutions will be biased low relative to the total seismic moment of $31 \times 10^{27}$ dyne-cm determined by surface-wave analysis (Osada and Abe, 1981).

Source time functions were deconvolved from
33 long-period $\mathrm{P}$-wave seismograms using the single station time-domain inversion technique of Ruff and Kanamori (1983). This procedure results in individual moment rate functions that match the associated seismograms almost perfectly, allowing us to concentrate on the relative behavior of the source functions. We used a $2 \mathrm{~s}$ interval for the time function, and $160 \mathrm{~s}$ of record. In a previous study of the Banda Sea event, a hypocentral depth of $100 \mathrm{~km}$ and a fault plane with a strike of $\mathrm{N} 80^{\circ} \mathrm{E}$, a dip of $48^{\circ} \mathrm{SE}$ and a rake of $52^{\circ}$ were determined by surface-wave analysis (Osada and Abe, 1981). We chose to further investigate the depth and mechanism of the rupture by deconvolving source functions assuming half space Green's functions at source depths of 100 and 130 $\mathrm{km}$ for rakes varying between $30^{\circ}$ and $50^{\circ}$. Reverberations in an ocean layer $3 \mathrm{~km}$ deep were included in the Green's functions. The resulting source functions are shown in Fig. 3 for two stations that are representative of the different characteristic waveshapes. For a source depth of $100 \mathrm{~km}$, the character of the moment rate func- 


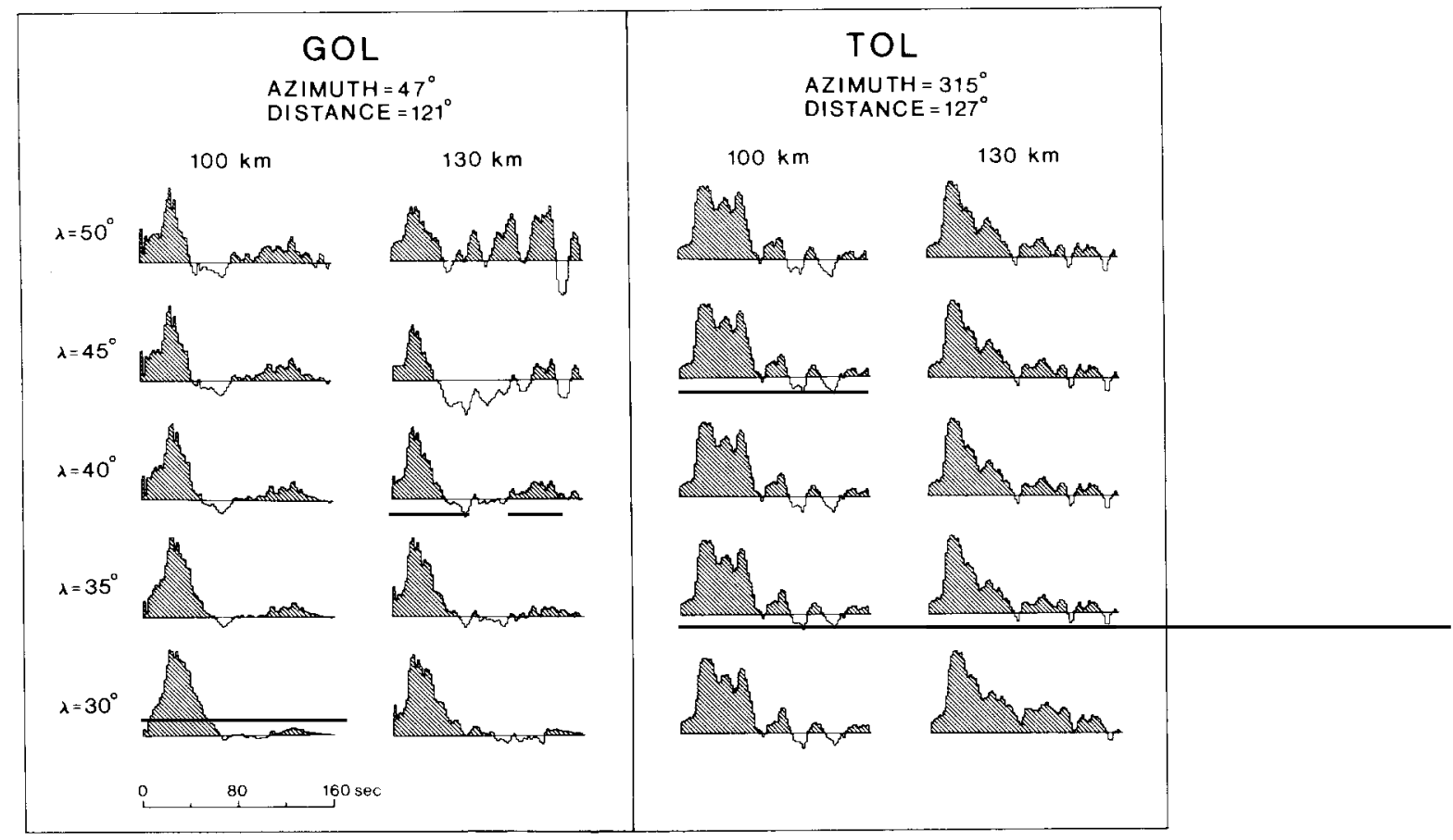

Fig. 3. Source time functions for stations GOL and TOL obtained by single station time-domain deconvolutions. The source time functions were deconvolved assuming source depths of 100 and $130 \mathrm{~km}$ for a range of slip directions. The source functions are most compatible for a rake of $40^{\circ}$ and a depth of $130 \mathrm{~km}$.

tions at the two stations does not change significantly with varying rake. GOL exhibits one pulse of moment release with a duration of about $50 \mathrm{~s}$, while TOL has three pulses of moment release with a total duration of approximately $65 \mathrm{~s}$. Substantial horizontal directivity would be required to produce this $15 \mathrm{~s}$ azimuthal variation, but we found that the systematic azimuthal variations expected for such directivity were not apparent in the suite of source functions deconvolved at this depth. Instead we observed abrupt azimuthal changes in moment rate functions, which cannot be interpreted using standard directivity analysis due to the absence of consistent features moving out across the azimuth range. The large inferred directivity would also be inconsistent with the lack of asymmetry in the surface wave radiation patterns determined by Osada and Abe (1981).

For a source depth of $130 \mathrm{~km}$, the character of the source time functions at both stations is more dependent on the assumed rake. While the mo- ment rate function at TOL remains fairly stable with changing slip direction, the time history for GOL simplifies with increasing strike-slip component. With a decrease in rake from $50^{\circ}$ to $40^{\circ}$ the complexity in moment release and virtually all of the negative moment rate at GOL are eliminated. In addition, for a rake near $40^{\circ}$ the source functions at the two stations become substantially more similar, with most of the moment release in one main pulse over a duration of $45-50 \mathrm{~s}$. There are still some azimuthal differences in the moment rate functions after $50 \mathrm{~s}$, but for the early part of the rupture the consistent features in the source time functions require minimal rupture directivity. The slight decrease in rake is consistent with the nodal $\mathrm{P}$ arrivals in the northeastern quadrant (Fig. 2). A rake of $40^{\circ}$ also satisfies the surface-wave observations, which principally require that the null axis trend about $\mathrm{N} 120^{\circ} \mathrm{E}$ (Osada and Abe, 1981). On the basis of this preliminary analysis, as well as additional tests of the sensitivity to strike 
and dip, we modified the previously determined mechanism to one given by a fault plane with a strike of $\mathrm{N} 80^{\circ} \mathrm{E}$, a dip of $48^{\circ} \mathrm{SE}$ and a rake of $40^{\circ}$ (Fig. 2). This small change in mechanism results in a long-period moment that is only a few percent higher than that of Osada and Abe (1981). This mechanism is also still consistent with the aftershock distribution which indicates that the fault plane is the southerly dipping plane (Osada and Abe, 1981).

To further explore the possibility that the centroid depth for the Banda Sea earthquake is greater than $100 \mathrm{~km}$, single station time-domain inversions were performed using our preferred mechanism for two representative stations; COR and COP (Fig. 4). We again used a $2 \mathrm{~s}$ interval for the time function and $160 \mathrm{~s}$ of record, and deconvolved the signals assuming half space Green's functions with source depths varying from 90 to $170 \mathrm{~km}$ in $10 \mathrm{~km}$ increments. With increasing depth, the long duration, blocky pulse character of the moment release at COP reduces to one pulse of shorter duration with a small precursor, much like the source function at COR. The greatest similarity in the moment rate functions between the two stations is achieved with a source depth of $130 \mathrm{~km}$, although differences persist for times greater than $50 \mathrm{~s}$ into the rupture.

We can evaluate the trade-off between source function and assumed source depth on the basis of the calculations performed by Christensen and Ruff (1985). Source depths greater than $130 \mathrm{~km}$ appear to overestimate the depth, as evidenced by complication of the source function with multiple, periodic pulses following the main pulse of moment release. This ringing effect is characteristic of overestimating the depth for shallow events, and is observed at both stations, although the periodicity of the later pulses is particularly apparent at COP. Depths less than $130 \mathrm{~km}$ appear to underestimate the centroid depth resulting in broadening of the source function, which is also a diagnostic effect for shallow events. Again, this effect is more pronounced at COP than COR.

The source time functions obtained by single station deconvolution from all 33 long-period Pwave seismograms with our preferred mechanism and a point source depth of $130 \mathrm{~km}$ are shown in

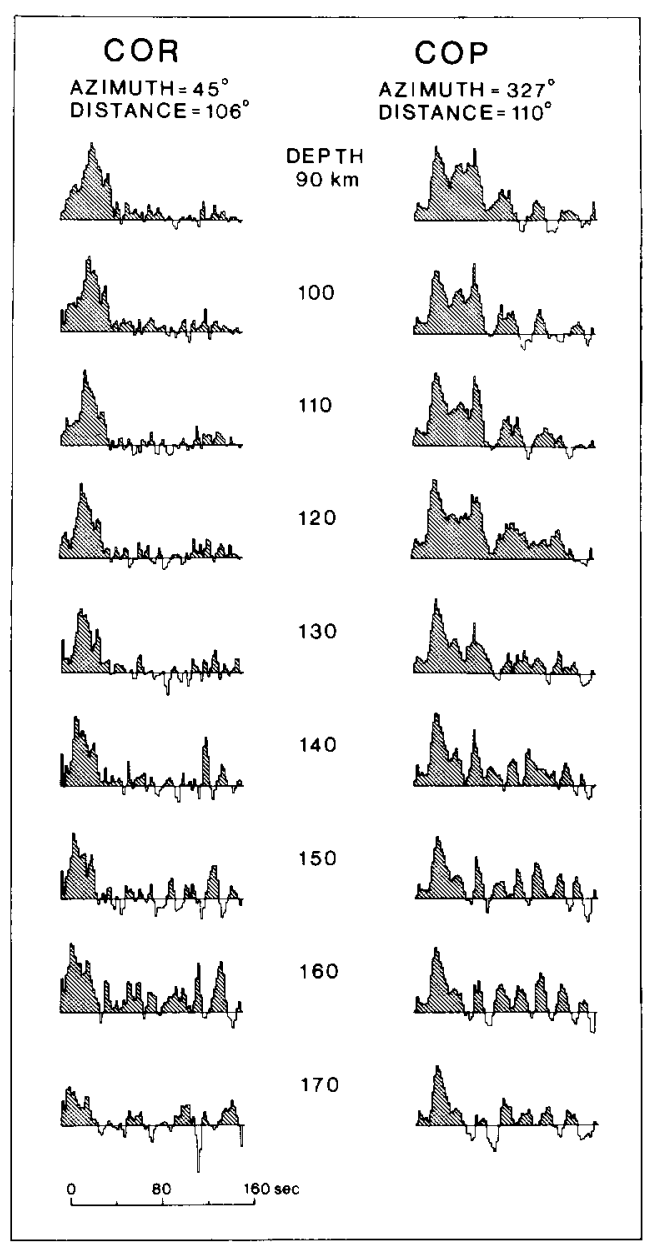

Fig. 4. Deconvolved source time functions for stations COR and COP for a range of point source depths from 90 to 170 $\mathrm{km}$. The mechanism has a strike of $\mathrm{N} 80^{\circ} \mathrm{E}$, a dip of $48^{\circ} \mathrm{SE}$ and a rake of $40^{\circ}$. The character of the source time functions for the two stations becomes most similar at a depth of about $130 \mathrm{~km}$.

Fig. 5. The characteristics of the source functions are generally consistent at all azimuths, despite the dramatic waveform differences. The source time functions exhibit a low moment rate level for the first $8-10 \mathrm{~s}$ followed by an abrupt increase in moment release. The high moment release continues until approximately $44 \mathrm{~s}$, when it decreases rather gradually and is followed by low to no moment release. There is significant ringing at stations to the northwest, which has some coherent behavior. The stations to the northeast are 

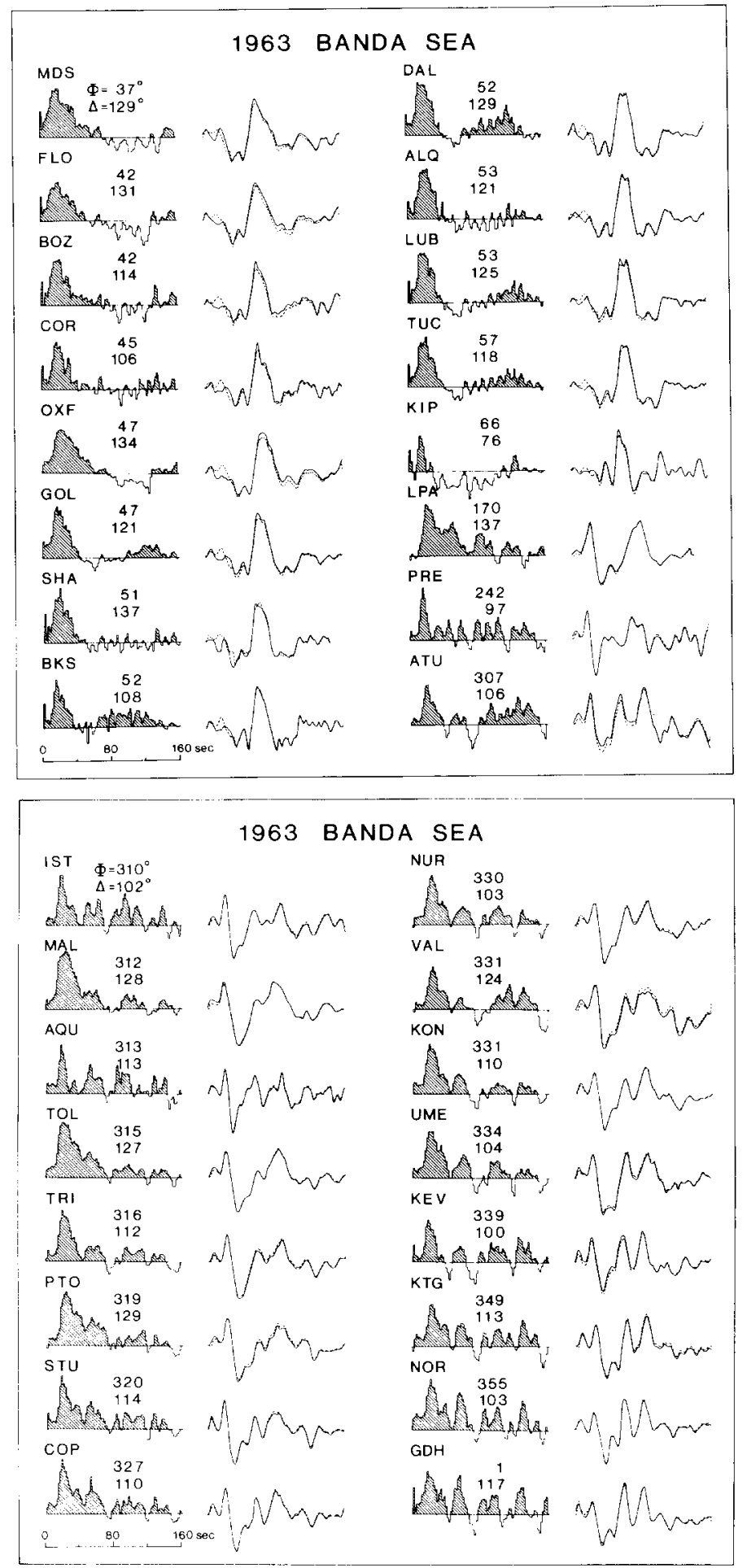

Fig. 5a, b. Source time functions for the 1963 Banda Sea earthquake obtained by individual station time-domain deconvolutions along with observed and synthetic traces. The solid trace is the observed seismogram and the dashed trace is the synthetic seismogram for the source time function shown at each station. The source time functions show slow initiation of the rupture and one main pulse of moment release. 
very quiet in the same interval, so we feel that this is probably an effect of laterally varying Earth structure above the source rather than a source effect. It should be noted that the synthetic traces do not exactly fit the first $10 \mathrm{~s}$ of the observed waveforms at stations to the northeast. Better agreement between the observed and synthetic traces was obtained with shallower depths of 90-110 km; however, as shown before, the shallower depths produce azimuthal patterns of the moment rate function that cannot be readily interpreted. It is possible that the presence of the slab results in an azimuthal variation in apparent source depth, with stations to the east recording relatively early surface reflections. Since the stations to the northeast are very nodal for direct $\mathrm{P}$, but not for the later surface reflection arrivals, the degree of misfit to the early part of the observed traces is not unacceptable.

While these single station deconvolutions unveil the principle character of the moment rate functions, there are incoherent features between adjacent stations that reflect noise due to unaccounted-for receiver effects and inappropriate Green's functions. To suppress these effects, we have also performed a multi-station deconvolution analysis, which also provides a parameterization of the spatial effects of the finite rupture.

\section{Simultaneous inversions}

To establish the spatial characteristics of the source process of the Banda Sea earthquake and to further constrain the source depth, we used a slightly modified version of the one-dimensional fault simultaneous inversion technique of Kikuchi and Kanamori (1982). The modification simply involved deconvolving out wavelets for a trapezoid source rather than for a ramp response, which proved more stable for the long duration source function of the Banda Sea event. This inversion attempts to fit all of the waveform data using a ribbon fault model, thus the relative amplitudes of the signals between stations become important. As previously discussed, most of the $\mathbf{P}$ waveforms were recorded at diffracted distances, consequently the absolute amplitudes are not reliable.
Deconvolution with appropriate diffracted wave Green's functions is of course theoretically possible, but techniques for computing such Green's functions with sufficient bandwidth are not available, nor is the deep mantle Earth structure well enough known. To empirically evaluate the diffraction losses, the biased moments $\left(M_{o}^{\prime}\right)$ obtained from the individual station deconvolutions, for which the amplitudes were not corrected for diffraction, were plotted versus epicentral distance (Fig. 6). A logarithmic fall-off from the long-period surface-wave moment ( $M_{o}$ ) with suprisingly little scatter is observed. To remove this inherent range dependent amplitude bias, the moments were normalized to $M_{o}$ for use as station weighting factors in the simultaneous inversion, giving each station comparable weight. Non-diffracted stations were not corrected. This procedure forces the simultaneous inversions to extract the source finiteness principally from the waveform shapes.

Using 10 azimuthally distributed stations and a finite fault length of $100 \mathrm{~km}$ with $20 \mathrm{~km}$ spacing between point sources, we performed several ribbon fault simultaneous inversions. The inversions were run for source depths ranging between 90 and $170 \mathrm{~km}$ in $10 \mathrm{~km}$ increments, a half space P-wave velocity of $7.4 \mathrm{~km} \mathrm{~s}^{-1}$, and for synthetic wavelets with three different source trapezoids (Fig. 7). The three symmetric source trapezoids had rise times, $\tau$, and rupture durations, $t_{c}$, of 3 and $5 \mathrm{~s}, 4$ and $6 \mathrm{~s}$ and 5 and $7 \mathrm{~s}$. The inversions

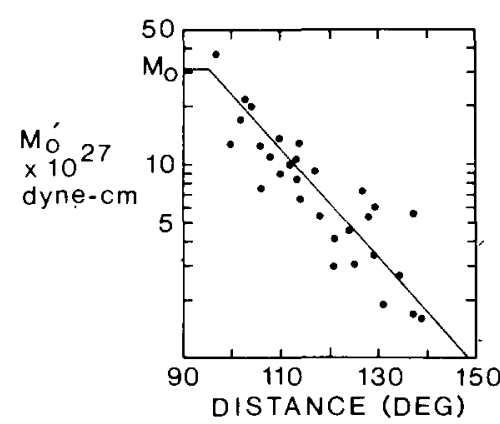

Fig. 6. The effect of diffraction on biased moments $\left(M_{o}^{\prime}\right)$, obtained from single station time-domain deconvolution using a source depth of $130 \mathrm{~km}$, is shown as a function of epicentral distance. A logarithmic fall-off is observed from the long-period surface wave moment, $M_{o}$, of $31 \times 10^{27}$ dyne-cm, due to omitting the diffraction effects in the Green's functions. 


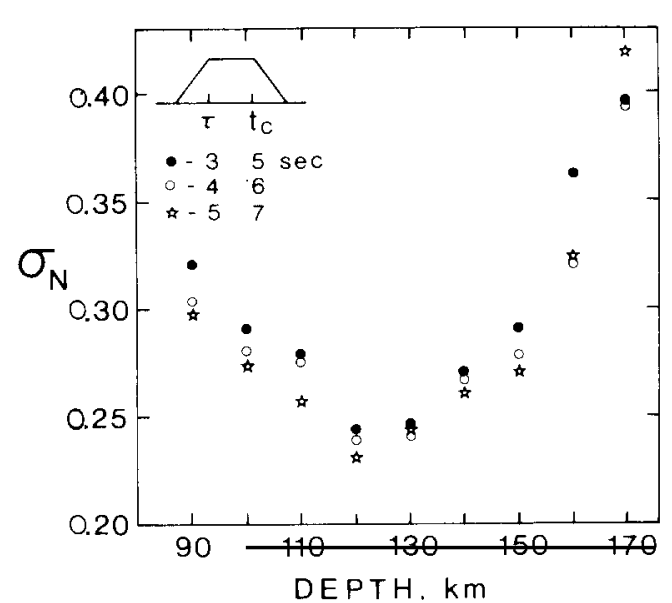

Fig. 7. The residual waveform mismatch for simultaneous inversions of a 10 station subset of $P$ waves assuming a $100 \mathrm{~km}$ long ribbon fault is shown for several source depths. The effect of the assumed trapezoidal source function used in the source wavelets is shown for three cases.

were iterated until improvement in the fit to the waveforms was no longer significant (about 15 iterations), and the final residual waveform mismatch was plotted versus depth. For each inversion with a different synthetic wavelet, a minimum in residual variance occurred at a depth of 120 $\mathrm{km}$, although depths between 110 and $140 \mathrm{~km}$ give only slightly higher variance. The variance for depths from 90 to $160 \mathrm{~km}$ is smallest for the source wavelet with $\tau=5 \mathrm{~s}$, therefore we used this wavelet in the subsequent analysis of the entire data set.

The waveform fits obtained with the ribbon fault inversion adequately match the observed traces at all azimuths for the first $60 \mathrm{~s}$ of the rupture. The agreement between the synthetic and the observed waveforms for stations to the northeast was particularly good for the entire $160 \mathrm{~s}$ window. However, the synthetic waveforms for stations to the northwest agreed satisfactorily with the observed traces for only the first $60 \mathrm{~s}$, and misfit the remainder of the signal. This is consistent with the azimuthal variation of single station deconvolutions in Fig. 5. We found that very little along-strike directivity could be stably resolved with the ribbon fault inversions. Great earthquakes such as the Banda Sea event may certainly involve significant vertical extent of the fault plane or a change in mechanism during the rupture, particularly in regions of contorted lithosphere. While the occurrence of either or both factors could explain the lack of agreement between the observed and synthetic waveforms later than $1 \mathrm{~min}$ into the signals at northwestern stations, accounting for the vertical extent of the fault plane is much more straightforward.

The two dimensional expansion of the source area during the rupture process of the Banda Sea earthquake was investigated using the iterative simultaneous deconvolution technique of Kikuchi and Fukao (1985). This procedure also deconvolves trapezoid response wavelets from the observations, and requires that the fault plane be a gridded network of point source locations. The entire data set of 33 stations was used in the inversion. The orientation of the fault plane was prescribed by the mechanism previously determined in this study. We allowed the rupture to extend over a fault area of $100 \times 100 \mathrm{~km}^{2}$ and specified $25(5 \times 5)$ grid points with an equal spacing of $20 \mathrm{~km}$ on the fault plane. The upper boundary of the fault was placed at $100 \mathrm{~km}$ depth and the epicenter of the main shock was centrally located with respect to the fault length and at the shallowest grid point $(107 \mathrm{~km})$. The deconvolution was repeated for 15 iterations with a $5 \mathrm{~s}$ rise time for the synthetic wavelets. The residual waveform variance after 15 iterations was $25 \%$.

The resultant synthetic waveforms are compared with the observed signals in Fig. 8. The waveform agreement is good at all stations with the exception of LPA, which is transitional between the two characteristic types of waveforms, and PRE, which is a less reliable horizontal component recording. The azimuthal distribution is not uniform, but there are comparable numbers of the two characteristic waveshapes. The agreement between the observed and synthetic traces at stations to the northwest is significantly improved over that obtained with the one dimensional, single depth rupture models, although the extra cycle near $80 \mathrm{~s}$ in the waveforms to the NNW is still not well modeled. A slight change in orientation of the fault plane $80 \mathrm{~s}$ into the rupture may be responsible for this complexity, but forward modeling 


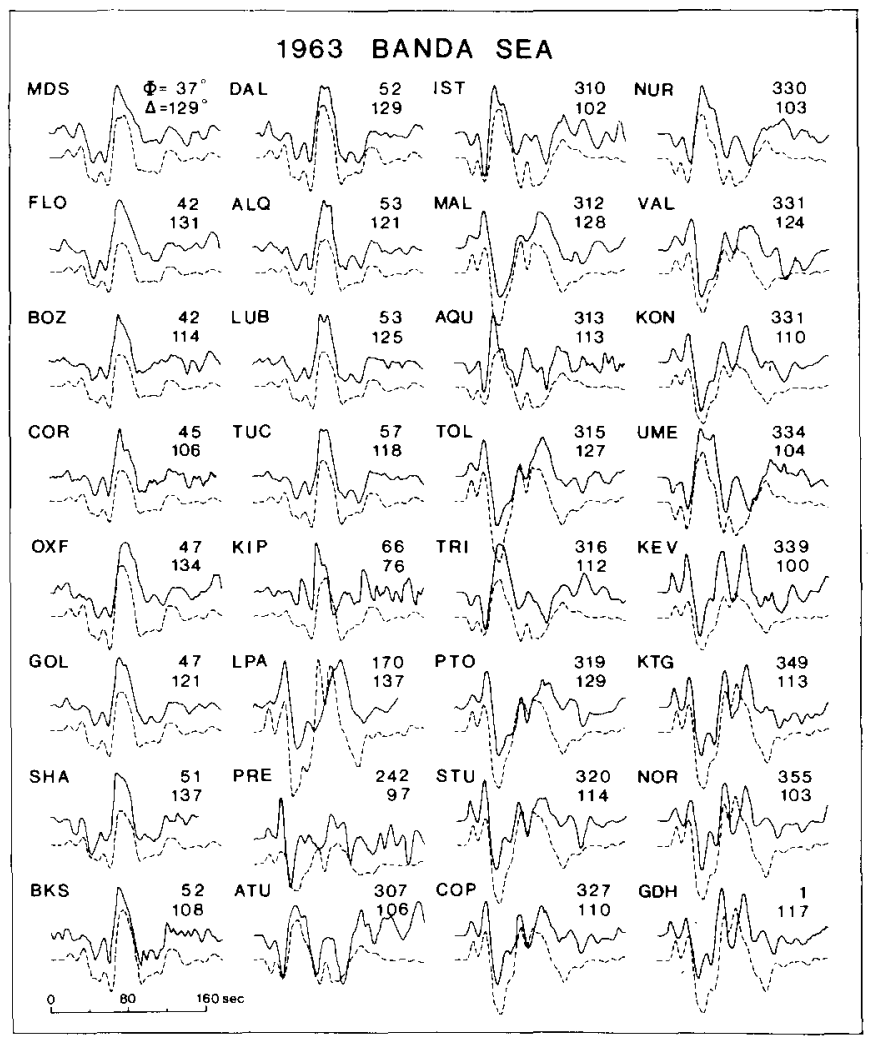

Fig. 8. Comparison between observed (solid) waveforms and synthetic (dashed) waveforms corresponding to the two dimensional simultaneous deconvolution discussed in the text. The amplitudes of the observed and synthetic have true relative scale; however, the data have been corrected by the moment anomalies obtained by single station deconvolutions.

experiments indicated a severe lack of resolution of any such late mechanism change.

Figure 9 shows the temporal and spatial distribution of subevents on the fault indicated by the inversion, as well as the point source time sequence and moment rate function that would be observed at a station with an azimuth perpendicular to the fault $\left(\mathrm{N} 10^{\circ} \mathrm{W}\right)$. The relative sizes of the subevents are proportional to the symbol sizes. On the basis of the spatial and temporal distribution of the deconvolved source history, we can characterize the source process of the Banda Sea earthquake. The moment release was low for the first $20 \mathrm{~s}$, initiating at depths near $122 \mathrm{~km}$, and expanding laterally and downdip to approximately 170 $\mathrm{km}$. The largest moment rate pulse (comprised of subsubevents 6,9 , and 4) ruptured shallower segments of the fault plane, between 110 and $130 \mathrm{~km}$, during the time interval of 25 to 45 s. Smaller subevents occurring in the final stage of the rupture (after $50 \mathrm{~s}$ ), are distributed along the boundaries of the fault plane, and are not reliably resolved in space or time by the deconvolution.

The moment rate function in Fig. 9 is very consistent with the common features in the moment rate functions obtained by single station time-domain deconvolutions in Fig. 5. Both procedures indicate small precursory rupture followed by an abrupt increase in moment release, with the majority of moment release occurring in one main pulse. The total seismic moment of the three largest subevents in the finite fault inversion, which make up the main pulse of moment release, is $7.9 \times 10^{27}$ dyne-cm. This is one half of the total moment of the deconvolved moment rate function, which is itself a factor of two lower than the surface wave 


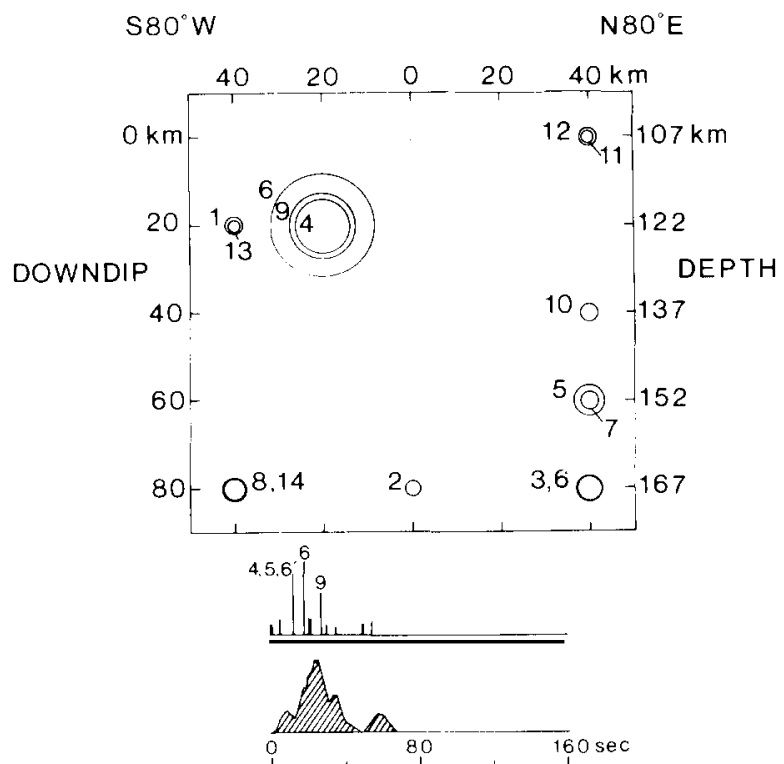

Fig. 9. Spatial distribution of subevents for the 1963 Banda Sea earthquake obtained by the finite fault inversion. The radius of circles is proportional to the seismic moment of the individual subevents and the numbers indicate the relative time sequence of the subevents. The moment rate function and source spike train for a station at a distance of $90^{\circ}$, and an azimuth of $\mathrm{N} 10^{\circ} \mathrm{W}$ are shown below to indicate how the sequence of subevents is manifested in the far field.

moment. It is likely that the amplitude normalization procedure that was needed for the diffracted signals, in addition to the bandlimited character of the data, leads to an unreliable moment.

It is clear that the subtle details of the deconvolved time history are poorly resolved. The spatial distribution of the point sources in Fig. 9 suggests an irregular, rather than a smoothly propagating rupture. However, the simultaneous deconvolution procedure is prone to some instability in the fine character of the deconvolved source sequence. To determine the overall stability of the inferred spatial and temporal characteristics of the rupture, we compared the moment rate functions and deconvolved subevent time sequences from several different simultaneous inversions (Fig. 10), in which we varied the fault dimensions, source mechanism, and parameters of the unit source trapezoid. The details of the timing, spatial distribution and moment of the subevents do vary

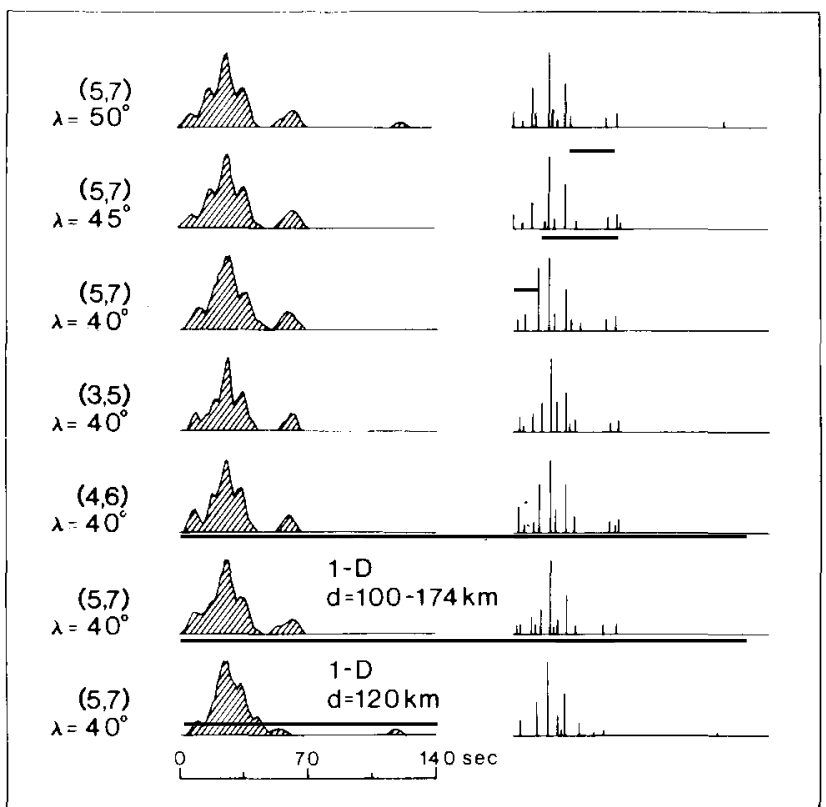

Fig. 10. Test of the stability of the moment rate functions obtained by simultaneous deconvolutions for small changes in rake, $\lambda$, of the source mechanism, and unit wavelet trapezoid parameters (given in parentheses). The moment rate functions are shown on the left and the deconvolved spike train sequences are on the right, with the station being at a distance of $90^{\circ}$ and an azimuth of $\mathrm{N} 10^{\circ} \mathrm{W}$. The 1-D cases are for ribbon faults extending in the downdip direction and along the strike direction.

somewhat with changing fault parameters. The distribution of the smaller subevents, particularly those in the late stages of the rupture, is not stable from one case to another. However, in every case, the rupture initiates at shallow depths, with the largest subevents occurring between 110 and 130 $\mathrm{km}$. Slip then expands laterally and downdip to approximately $170 \mathrm{~km}$. Despite the variation in timing, spatial distribution and moment of the subevents, the overall moment rate function is quite well determined. The moment rate functions proved stable for different source wavelet trapezoid parameters as well, and even for a ribbon fault extending downdip from 100 to $174 \mathrm{~km}$ (Fig. 10). While not well resolved, allowing depth variation does give significant improvement over the ribbon faults constrained to a single depth; we therefore feel that at least $50 \mathrm{~km}$ of vertical finiteness is 
required by the data. Of course, an alternate parameterization in which the mechanism was allowed to change may weaken this conclusion, however, the relocated aftershocks of the event (Osada and Abe, 1981) do suggest a $50 \mathrm{~km}$ depth range for the mainshock rupture zone. The increase in centroid depth over that used by Osada and Abe (1981) (96 km) results in about a 5\% increase in the long-period moment, which is insignificant given the uncertainty in the mechanism.

The general character of the rupture process of the Banda Sea earthquake was previously determined by analysis of surface waves (Osada and Abe, 1981), however, this analysis of the body waves has contributed to our understanding of this large event. The majority of moment release has been determined to have occurred 25-45 s into the rupture and the depth extent of the principal moment release has been constrained to a depth range of $100-130 \mathrm{~km}$. Although we have characterized the rupture process of the Banda Sea earthquake both temporally and spatially, it is important to also consider its tectonic implications.

\section{Discussion}

The most striking feature of the Banda arc is the $90^{\circ}$ bend in the subduction zone at its eastern end (Fig. 1). This change in trend has been attributed to north-northwesterly collision of the Australian continental shelf with the trench (Fitch, 1970, 1972; Cardwell and Isacks, 1978; McCaffrey et al., 1985) coupled with the westward movement of the Pacific plate (Katili, 1975). Detailed seismicity studies of the Banda arc reveal a continuous zone of intermediate depth activity which follows the curvature of the arc (Fitch, 1970; Fitch and Molnar, 1970; Cardwell and Isacks, 1978). Depth contours to the top of the seismic zone (Fig. 1) represent the geometry of the subducted lithosphere. The seismic zone dips steeply along the southern margin, which extends westward to the Java region, and the dip is more gradual along the eastern margin. In the region of maximum curvature connecting these areas, the seismicity indicates very strong but apparently continuous contortion.

Increased seismic activity in the hinge region, attributed to greater stresses from the contortion of the lithosphere, has been observed at all depths (Fitch, 1970; Fitch and Molnar, 1970; McCaffrey et al., 1985). The epicenters of events in the region of the November 4,1963 event, from $126^{\circ}-132^{\circ} \mathrm{E}$, are shown in Fig. 11. Events with $m_{b} \geq 5.0$ and depths of $60-150 \mathrm{~km}$ reported in the NOAA catalogue for the years 1960-1980 are plotted. Intense activity is observed in the hinge region near the location of the 1963 event.

The focal mechanism solution for the 1963 event has a quite steeply dipping tension axis and a nearly horizontal compression axis which parallels the strike of the slab (Fig. 11). This orientation of stress axes is characteristic of intermediate depth events in this region of the Banda arc (Cardwell and Isacks, 1978). Harvard centroid moment tensor solutions for events in the depth range of $60-200 \mathrm{~km}$ for the years 1977-June 1985 are shown in Fig. 12. Nearly all of the events involve oblique thrusting within the subducted slab. In all cases, the axes of minimum compressive stress ( $T$ axes) are oriented parallel to the dip of the seismic zone, indicating that downdip slab pull is important. The orientations of the tension axes track the change in dip of the slab around the

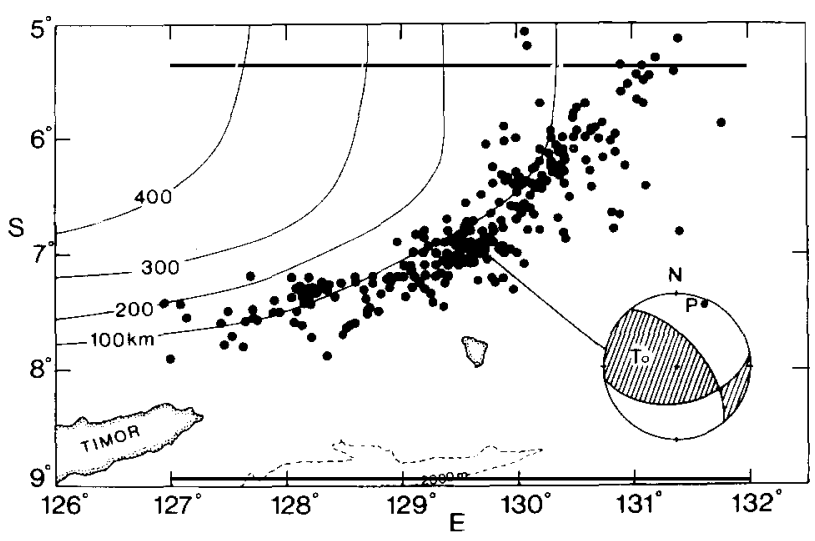

Fig. 11. Seismicity of the Banda arc region and mechanism of the 1963 event. The events are those with $m_{b} \geq 5.0$, and depths of $60-150 \mathrm{~km}$ reported in the NOAA catalogue for the years from 1960-1980. The solid curves are seismic depth contours in kilometers (Cardwell and Isacks, 1978). 


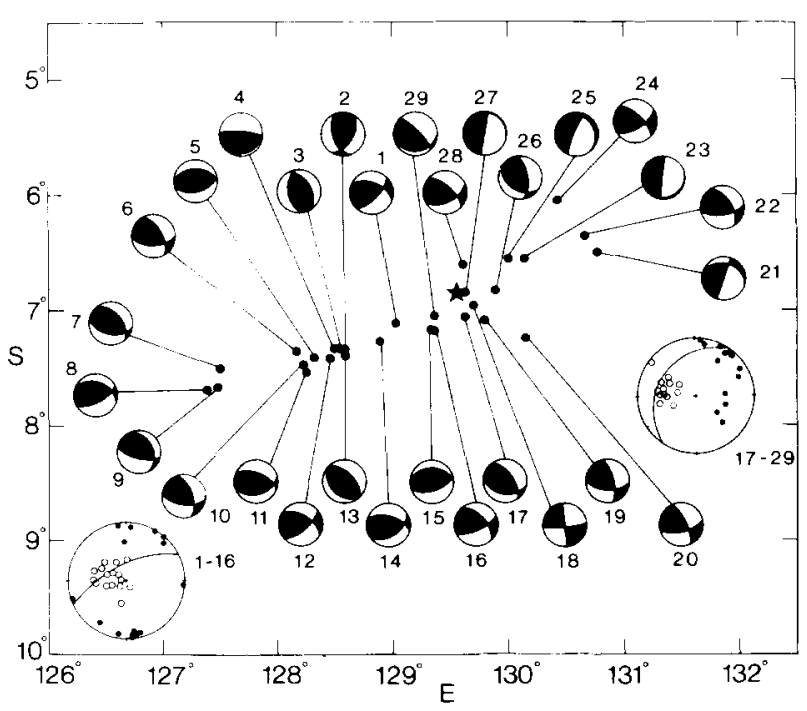

Fig. 12. Harvard, centroid moment tensor solutions for earthquakes in the Banda are region. The events are those with depths of $60-200 \mathrm{~km}$ for the years 1977-June 1985. In each mechanism, solid quadrants represent compressional first motions, open quadrants represent dilatations, with the solution for the major double couple being shown. The large focal spheres show the orientation of $\mathrm{T}$ axes (open circles) and $\mathrm{P}$ axes (solid circles) for these mechanisms, and the local orientation of the slab. The star indicates the location of the 1963 Banda Sea earthquake.

bend in the arc, plunging steeply in a northwesterly direction for mechanisms 1-16 and less steeply and in a more westerly direction for mechanisms 17-29. The pressure axes, however, are consistently oriented in a northeast direction for events throughout the hinge region. This stability in orientation indicates a regional compression arising from contortion of the lithosphere. The rotation of the tension axes and pervasive horizontal compression from contortion of the slab clearly reflect the influence of the curved seismic zone on the stress axes orientations (Fitch and Molnar, 1970; Cardwell and Isacks, 1978; McCaffrey et al., 1985).

It has been suggested that the Banda Sea earthquake ruptured the entire thickness of the elastic part of the slab, with slip initiating at $100 \mathrm{~km}$ and rupturing to greater depths (Osada and Abe, 1981). Osada and Abe (1981) interpreted the 1963 event as an offset of the subducted plate, with frequent events of this nature possibly accumulating enough offset to be visible in the seismic zone. This concept of the deformation of the subducted plate is illustrated in Fig. 13, where the accumulated offset of the plate is emphasized.

The focal sphere in Fig. 13 is a cross-sectional projection of the mechanism of the Banda Sea event. In this projection, the fault motion is not purely dip-slip, but has an oblique component, reflecting the fact that neither fault plane parallels the slab strike. The body-wave modeling in this study indicates that Osada and Abe (1981) were correct in asserting that the Banda Sea earthquake probably ruptured the entire elastic part of the slab, but clearly, the event is not simply a downdip offset of the subducted plate. Instead, the mechanism is strongly influenced by the lateral compression induced by contortion of the subducted lithosphere. Although the complexity of the hinge region complicates interpretation of the tectonic process, it is possible that this plate detachment is occurring at the leading edge of the subducted Australian continental slope. McCaffrey et al. (1985) estimated that some continental crust has been subducted in this region, and the

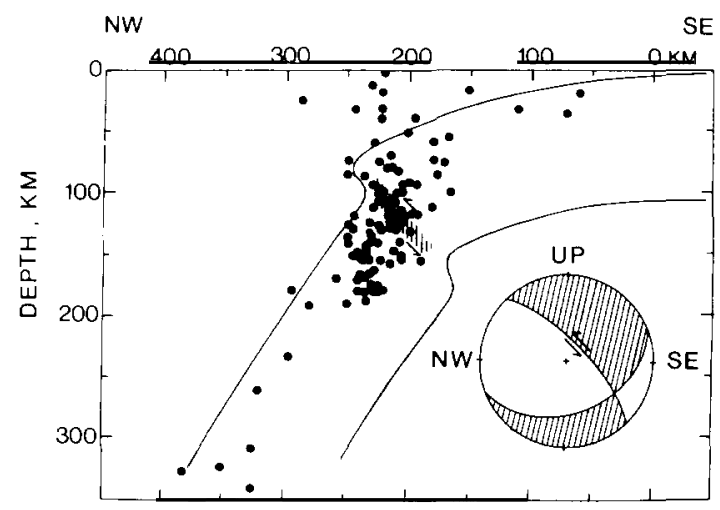

Fig. 13. Vertical cross-section through the Timor trough in the region of the 1963 Banda Sea earthquake and a cross-sectional projection of the focal mechanism. The events are those with $m_{b}$ greater than 5.0 reported in the ISC for the years 1964 through 1976. The fault plane of the 1963 event is shown by the hatched region. Arrows on both the schematic illustration of the slab and the fault plane of the mechanism indicate relative motion of the rupture. Hatched quadrants represent compressional first motion, open quadrants represent dilatations. (Modified from Osada and Abe, 1981.) 
edge may be at depths of $75-150 \mathrm{~km}$, which is consistent with the fault geometry in Fig. 13. McCaffrey et al. (1985) have also detected a zone of intraplate activity west of Timor (Fig. 1), which appears to represent a tear fault separating regions of old oceanic lithosphere to the west from continental shelf to the east. This suggests that variable resistance to subduction along the arc produces intraplate activity. Buoyancy of the continental crust, which has slowed the convergence rate in this region (Spence, 1986), appears to have produced the conditions for the occurrence of the Banda Sea event.

\section{Conclusions}

We have characterized both temporally and spatially the rupture process of the 1963 Banda Sea earthquake. Moment rate functions deconvolved from long-period $P$ waves, using both single station and multiple station time-domain deconvolution methods, show a gradual buildup of moment release during the first $20 \mathrm{~s}$, with a subsequent main pulse of moment release. This primary moment release occurred from $25-45 \mathrm{~s}$ into the rupture in the depth range of $100-130 \mathrm{~km}$. The rupture expanded laterally and downdip from the hypocenter to a depth of approximately $170 \mathrm{~km}$. Very little horizontal directivity can be resolved, indicating horizontal fault dimensions of no more than about $100 \mathrm{~km}$. We have also considered the tectonic implications of the Banda Sea earthquake, which appears to involve an offset of the subducted slab, perhaps along the leading edge of the Australian continental shelf. The regional stress regime involves downdip slab pull and along strike compression arising from contortion of the lithosphere at the eastern end of the Banda arc.

\section{Acknowledgements}

We thank Y. Fukao and M. Kikuchi for information on their analysis of the Banda Sea earthquake. Larry Ruff, Susan Schwartz and Susan Beck provided constructive criticism of the manuscript. This research was supported by NSF
Grant EAR-8451715, a Shell Faculty Career Initiation Grant, and an Exxon Education Foundation Grant.

\section{References}

Bullen, K.E., 1963. An Introduction to the Theory of Seismology. Cambridge University Press, New York, 381 pp.

Cardwell, R.K. and Isacks, B.L., 1978. Geometry of the subducted lithosphere beneath the Banda Sea in eastern Indonesia from seismicity and fault plane solutions. J. Geophys. Res., 83: 2825-2828.

Christensen, D.H. and Ruff, L.J., 1985. Analysis of the trade-off between hypocentral depth and source time function. Bull. Seismol. Soc. Am., 75: 1637-1656.

Fitch, T.J., 1970. Earthquake mechanisms and island are tectonics in the Indonesian-Phillippine region. Bull. Seismol. Soc. Am., 60: 565-591.

Fitch, T.J., 1972. Plate convergence, transcurrent faults, and internal deformation adjacent to Southeast Asia and the western Pacific. J. Geophys. Res., 77: 4432-4460.

Fitch, T.J. and Molnar, P., 1970. Focal mechanisms along inclined earthquake zones in the Indonesia-Philippine region. J. Geophys. Res., 75: 1431-1444.

Kanamori, H., 1971. Seismological evidence for a lithospheric normal faulting - the Sanriku earthquake of 1933. Phys. Earth Planet. Inter., 4: 289-300.

Katili, J.A., 1975. Volcanism and plate tectonics in the Indonesian island arcs. Tectonophysics, 26: 165-188.

Kikuchi, M. and Kanamori, H., 1982. Inversion of complex body waves. Bull. Seismol. Soc. Am., 72: 491-506.

Kikuchi, M. and Fukao, Y., 1985. Iterative deconvolution of complex body waves from great earthquakes - the Tokackj-Oki earthquake of 1968. Phys. Earth Planet. Inter., 37: $235-248$

Lynnes, C.S., Lay, T. and Ruff, L.J., 1985. Rupture process of the 1977 Sumba earthquake. EOS, 66: 957.

McCaffrey, R., Molnar, P., Roecker, S.W. and Joyodiwiryo, Y.S., 1985. Microearthquake seismicity and fault plane solutions related to arc-continent collision in the eastern Sunda arc, Indonesia. J. Geophys. Res., 90: 4511-4528.

Osada, M. and Abe, K., 1981. Mechanism and tectonic implications of the great Banda Sea earthquake of November 4, 1963. Phys. Earth Planet. Inter., 25: 129-139.

Ruff, L.J. and Kanamori, H., 1983. The rupture process and asperity distribution of three great earthquakes from longperiod diffracted $\mathbf{P}$ waves. Phys. Earth Planet. Inter., 31: 202-230.

Silver, P.G. and Jordan, T.H., 1983. Total moment spectra of fourteen large earthquakes. J. Geophys. Res., 88: 3273-3293.

Spence, W., 1986. The 1977 Sumba earthquake series: evidence for slab pull force acting at a subduction zone. J. Geophys. Res., 91: 7225-7239. 